\title{
U.S. Army Acquisition - The Program Office Perspective
}

Kristi L. Keeler

October 2005

SPECIAL REPORT

CMU/SEI-2005-SR-014 

= CarnegieMellon

= Software Engineering Institute

Pittsburgh, PA 15213-3890

\section{U.S. Army Acquisition - The Program Office Perspective}

CMU/SEI-2005-SR-014

Kristi L. Keeler

October 2005

Acquisition Support Program

Unlimited distribution subject to the copyright. 
This report was prepared for the

SEI Administrative Agent

ESC/XPK

5 Eglin Street

Hanscom AFB, MA 01731-2100

The ideas and findings in this report should not be construed as an official DoD position. It is published in the interest of scientific and technical information exchange.

This work is sponsored by the U.S. Department of Defense. The Software Engineering Institute is a federally funded research and development center sponsored by the U.S. Department of Defense.

Copyright 2005 Carnegie Mellon University.

NO WARRANTY

THIS CARNEGIE MELLON UNIVERSITY AND SOFTWARE ENGINEERING INSTITUTE MATERIAL IS FURNISHED ON AN "AS-IS" BASIS. CARNEGIE MELLON UNIVERSITY MAKES NO WARRANTIES OF ANY KIND, EITHER EXPRESSED OR IMPLIED, AS TO ANY MATTER INCLUDING, BUT NOT LIMITED TO, WARRANTY OF FITNESS FOR PURPOSE OR MERCHANTABILITY, EXCLUSIVITY, OR RESULTS OBTAINED FROM USE OF THE MATERIAL. CARNEGIE MELLON UNIVERSITY DOES NOT MAKE ANY WARRANTY OF ANY KIND WITH RESPECT TO FREEDOM FROM PATENT, TRADEMARK, OR COPYRIGHT INFRINGEMENT.

Use of any trademarks in this report is not intended in any way to infringe on the rights of the trademark holder.

Internal use. Permission to reproduce this document and to prepare derivative works from this document for internal use is granted, provided the copyright and "No Warranty" statements are included with all reproductions and derivative works.

External use. Requests for permission to reproduce this document or prepare derivative works of this document for external and commercial use should be addressed to the SEI Licensing Agent.

This work was created in the performance of Federal Government Contract Number FA8721-05-C-0003 with Carnegie Mellon University for the operation of the Software Engineering Institute, a federally funded research and development center. The Government of the United States has a royalty-free government-purpose license to use, duplicate, or disclose the work, in whole or in part and in any manner, and to have or permit others to do so, for government purposes pursuant to the copyright license under the clause at 252.227-7013.

For information about purchasing paper copies of SEI reports, please visit the publications portion of our Web site (http://www.sei.cmu.edu/publications/pubweb.html). 


\section{Table of Contents}

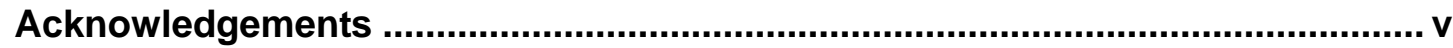

Executive Summary ................................................................................... vii

Abstract..................................................................................................... ix

1 Introduction ........................................................................................ 1

1.1 The Army Strategic Software Improvement Program ............................ 1

1.1.1 Survey of Acquisition Managers ….............................................. 3

1.1.2 Program Executive Officer Interviews................................... 3

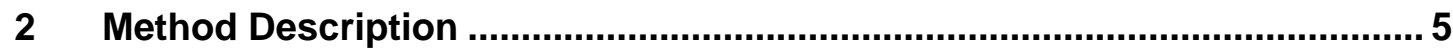

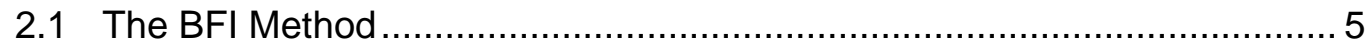

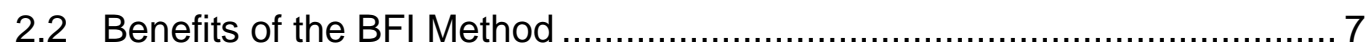

2.3 Potential for BFI Method Improvements .......................................... 8

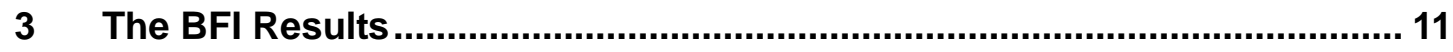

3.1 Theme: Risk Management......................................................... 12

3.1.1 What Was Found ............................................................ 12

3.1.2 What Could Be Improved ............................................... 12

3.1.3 An Exemplary Implementation ............................................ 13

3.2 Theme: Acquisition Process - Traditional vs. New Mandates ................. 13

3.2.1 What Was Found ............................................................... 13

3.2.2 What Can Be Improved..................................................... 14

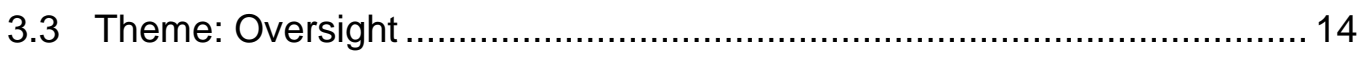

3.3.1 What Was Found ........................................................... 14

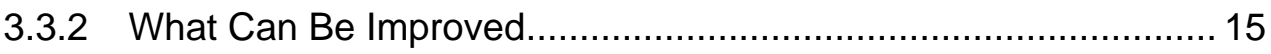

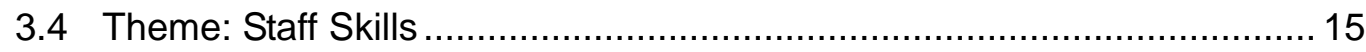

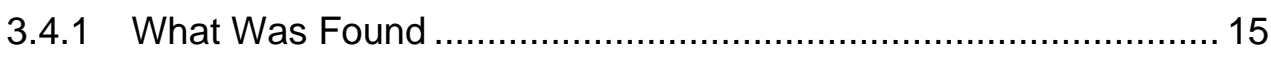

3.4.2 What Can Be Improved......................................................... 16

3.4.3 Suggested Improvement............................................. 16

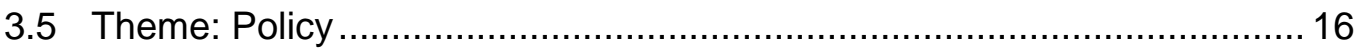

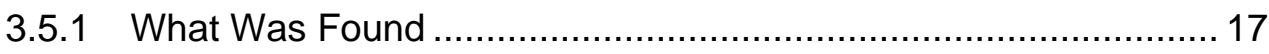

3.5.2 What Can Be Improved................................................... 17

3.5.3 Suggested Improvement .................................................. 18 
3.6 Theme: Career Development ................................................... 18

3.6.1 What We Found ............................................................. 18

3.6.2 What Can Be Improved ...................................................... 18

3.6.3 Suggested Improvement........................................... 18

3.7 Theme: Integrated Product Teams ..................................................... 19

3.7.1 What Was Found ............................................................. 19

3.7.2 What Can Be Improved ................................................... 19

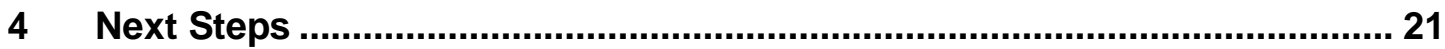

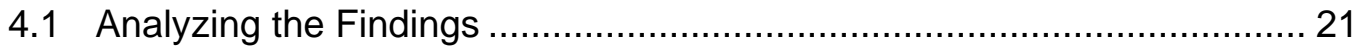

4.2 Using the Findings..................................................................... 22

4.3 Issues Related to Information Processing ....................................... 22

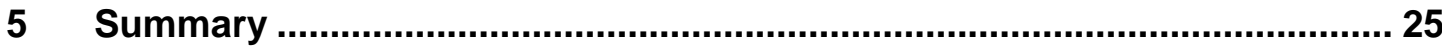

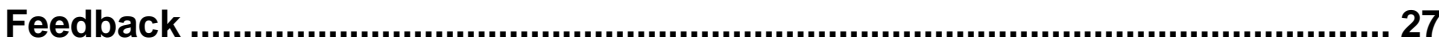

Appendix A Acronyms and Abbreviations...................................................... 29

Appendix B Benchmarking for Improvement Interview Questions ................. 31

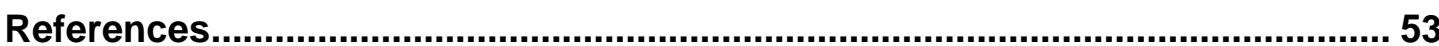




\section{List of Figures}

Figure 1: $\quad$ ASSIP Uses Improved Acquisition Processes to Yield Better Results ..... 2

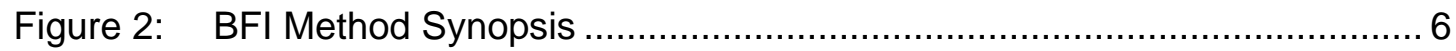

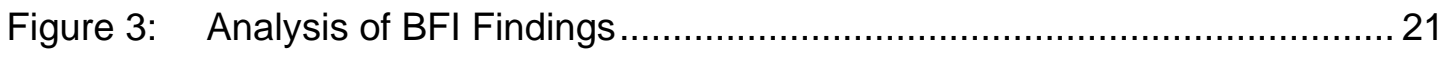

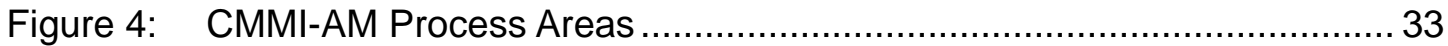




\section{Acknowledgements}

The author appreciates the untiring efforts of Stephen Blanchette, Jr. and Cecilia Albert of the Carnegie Mellon ${ }^{\circledR}$ Software Engineering Institute (SEI), and Dr. James Linnehan of the Office of the Assistant Secretary of the Army for Acquisition, Logistics and Technology. Their persistent and thoughtful comments greatly improved the quality of this report. The author also wishes to acknowledge the editorial assistance of the SEI's Susan Kushner.

Lastly, this work would not have been possible without the diligent efforts of the Department of Army Program Managers that allowed us to disrupt their schedule-sensitive days for interviews and the team of SEI staff that works for the Department of Army initiative. This group includes the BFI interviewers: SEI staff members Frank Sisti, Peter Capell, Ira Monarch, Benjamin Snyder, Lisa Brownsword, Kate Ambrose, Craig Meyers, Diane Gibson, and William Novak, and SEI visiting scientists Thomas Miller and John Mishler. Their notes and observations helped form the basis of the information presented here. Thank you all.

${ }^{\circledR}$ Carnegie Mellon is registered in the U.S. Patent and Trademark Office by Carnegie Mellon University. 


\section{Executive Summary}

The U.S. Army Strategic Software Improvement Program (ASSIP) is a multiyear effort to improve the way the Army acquires software-intensive systems. As part of the ASSIP, the Carnegie Mellon Software Engineering Institute examined 12 of the Army's Acquisition Category 1 (ACAT 1) programs using a method called Benchmarking for Improvement (BFI). The purpose of conducting the BFI engagements was to define the current state of acquisition practices across the Army to discover best practices currently in use by Army program offices, to identify the software challenges that extend across Army programs, and to brainstorm potential solutions and recommendations for Army-wide improvement. In addition, the BFI team provided each program manager (PM) with an independent view of program-level activities and made specific recommendations for improvement. A briefing provided to each program manager documented these recommendations.

This report documents the results of the interviews conducted during BFI engagements. The following list provides a high-level view of some of the themes that surface during the interviews:

- Risk management practices are not standardized and risks are inconsistently and insufficiently tracked, updated, and addressed.

- The acquisition policy changes that occurred during the past five years have created confusion and difficulties that are exacerbated by operational demands for rapid delivery of early capability.

- Oversight and monitoring of contractors' system engineering and management practices is not executed consistently.

- Program management offices do not employ personnel who have the specialized skills needed to respond to all of the demands of their jobs. In addition, TRADOC (Training and Doctrine Command) System Manager (TSM) groups are understaffed.

- Program management offices perceive Office of the Secretary of Defense (OSD) and Department of the Army (DA) policy and directives as being in constant flux, which makes it difficult to locate or develop interpretation expertise.

- Program management certification does not sufficiently recognize the value of developmental, operational, TSM, DA, or OSD assignments.

- The use of Integrated Product Teams (IPTs) is mandated; however, some programs do not execute them effectively. 


\section{Abstract}

The U.S. Army Strategic Software Improvement Program (ASSIP) is a multiyear effort to improve the way the Army acquires software-intensive systems. As part of the ASSIP, the Carnegie Mellon Software Engineering Institute (SEI) examined 12 of the Army's Acquisition Category 1 programs, using a method called Benchmarking for Improvement (BFI). The purpose of conducting the BFI engagements was to define the current state of the acquisition practices across the Army, to discover best practices currently in use by Army program offices, and to identify the software challenges that extend across Army programs. As part of the BFI process, the program management office and SEI interview teams worked together to identify Department of Army best practices and shortcomings in the overall acquisition process, as well as potential solutions and recommendations. In addition, the SEI team provided each program manager with an independent view of program-level activities and made specific recommendations for improvement. A briefing provided to each program manager documented these recommendations.

This report documents the results of the interviews conducted during BFI engagements. These results are of interest to Program Executive Office staffs, Program Management Office staffs, and Department of Army staffs that are involved in acquisition. 


\section{Introduction}

In late 2002, the Carnegie Mellon Software Engineering Institute (SEI) entered into a strategic agreement with the assistant secretary of the Army for acquisition, logistics, and technology (ASA(ALT)). This partnership, known as the Army Strategic Software Improvement Program (ASSIP), seeks to improve the Army's techniques for acquiring systems with high software content, called software-intensive systems, ${ }^{1}$ or SIS.

This special report presents the results of the ASSIP-sponsored examination of 12 of the Army's Acquisition Category (ACAT) 1 programs. Examinations were conducted from July 2003 to October 2004 using a method called Benchmarking for Improvement (BFI). The BFI method was designed to define the current state of the acquisition practices across the Army, to discover best practices currently in use by Army program management offices (PMOs), and to identify the software challenges that extend across Army programs. In addition, each Program Manager (PM) was provided an independent view of program-level activities and specific recommendations for improvement, which were documented in a briefing. The SEI is using this information to help guide the ASSIP improvement initiatives. By sharing this information with the acquisition functions of the other services, other government agencies, and industry, the SEI and the ASSIP hope to stimulate open discussions about SIS acquisition issues.

In order to understand these results, a brief review of the ASSIP is included in the next section. In addition, Sections 1.1.1 and 1.1.2 summarize the results of other ASSIP data collection efforts to help the reader develop a broader picture of the impact that acquisition improvement efforts are having on the Department of the Army (DA).

\subsection{The Army Strategic Software Improvement Program}

The ASSIP is a multiyear effort targeted at dramatically improving the way the Army acquires software-intensive systems. The ASA(ALT) initiated the ASSIP in 2002 as a means of helping the Army proactively respond to the challenges of developing systems that are increasingly dependent on software. Later, when Congress included Section 804 in the National Defense Authorization Act for Fiscal Year 2003, which required the services to develop

1 According to the Defense Acquisition University (DAU), a software-intensive system is one in which software represents the largest segment in one or more of the following criteria: system development cost, system development risk, system functionality, or development time [DAU 05]. 
plans for their software acquisitions, the ASSIP was shaped to address those requirements as well [PL 02].

Organizationally, two main groups compose the ASSIP. The Senior Steering Group (SSG), comprised of the PEOs, the Military Deputy (MILDEP) to the ASA(ALT), and the Director of the SEI, provides overall guidance to the effort. The ASSIP Action Group (AAG), consisting of representatives from each of the PEOs and from the Army Software Engineering Centers, as well as SEI technical staff members, develops and implements improvement strategies. The ASSIP is a partnership and the SSG and AAG are co-chaired by the Army and the SEI. Through this partnership, the SEI offers expert guidance on software acquisition and process issues, provides secretariat services to the SSG and AAG, and acts as a catalyst for change. As shown in Figure 1, ASSIP efforts are predicated on the idea that improved acquisition practices will lead to better systems and overall results.

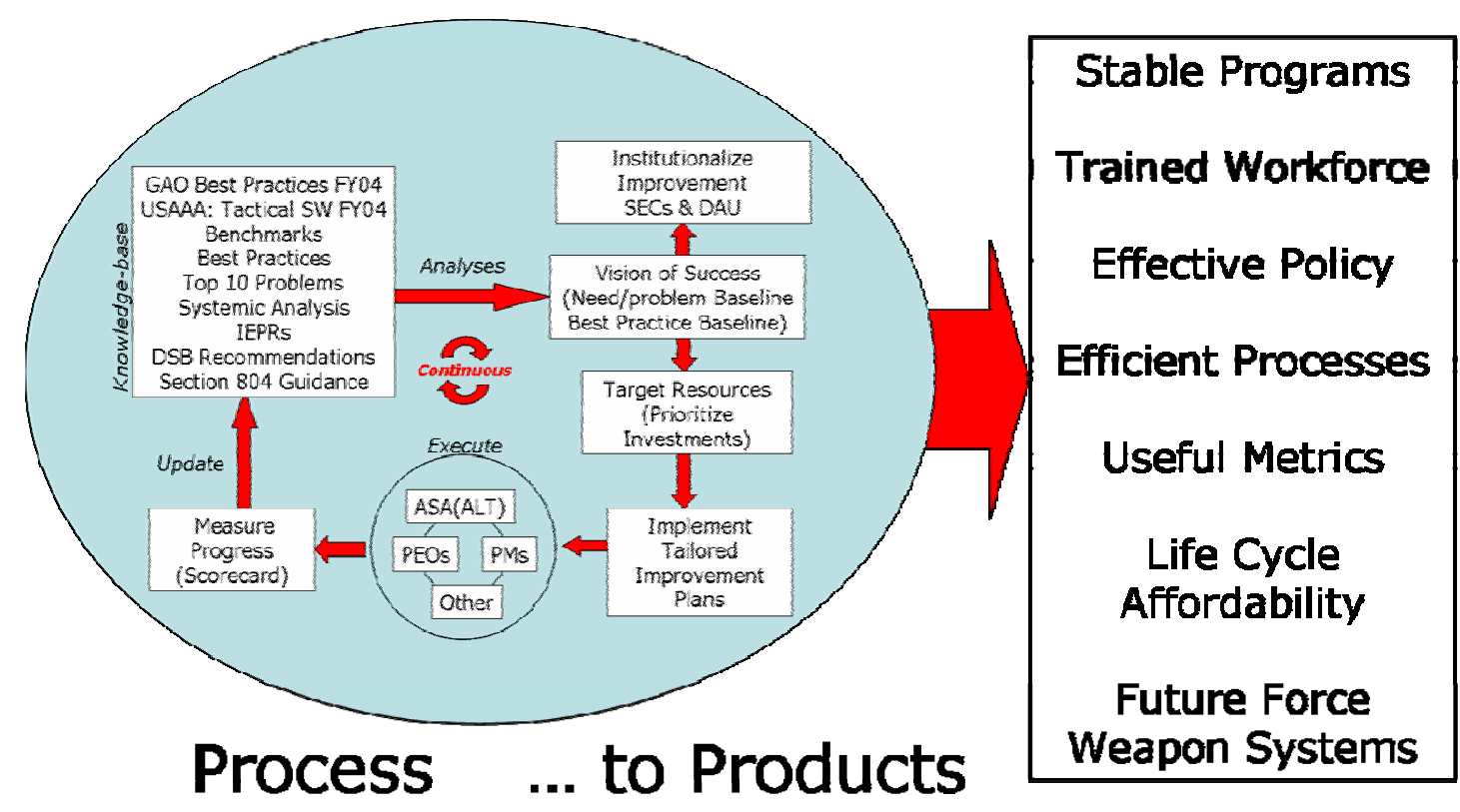

Figure 1: ASSIP Uses Improved Acquisition Processes to Yield Better Results

As with any improvement effort, an understanding of the baseline state of Army acquisition was needed for the ASSIP to be successful. While there was plenty of anecdotal evidence and speculation about the challenges to successful SIS acquisition, there was very little hard evidence about the need to focus on improvement. The SEI set about gathering the necessary evidence by surveying Army acquisition managers, interviewing PEOs, and participating in direct engagements with several critical Army PMOs using the BFI method. The survey and PEO interviews are described briefly below; the results of the BFI engagements are the subject of the body of this report. 


\subsubsection{Survey of Acquisition Managers}

The SEI made an initial attempt at characterizing the state of Army acquisition through a survey of Army acquisition managers. While the survey, conducted in 2003, proved useful to set ASSIP expectations about the range of potential problems, it did not provide reliable or sufficiently detailed information on which to base improvement strategies. Survey instructions were not adequately communicated to the target audience to achieve consistency among respondents. Many managers delegated responsibility for completing the survey to staff members whose backgrounds varied widely. Kasunic details the survey results and their limitations in a technical report [Kasunic 04].

\subsubsection{Program Executive Officer Interviews}

To gain the insights of the Army's senior acquisition professionals, the SEI conducted interviews with the PEOs from April 2004 through December 2004. Interview teams consisted of two SEI technical staff members, with one member acting as the primary interviewer and the other acting as the primary recorder. To provide consistency across the interviews, only two individuals acted as the primary interviewer during the course of the interviews.

Interviews were conducted using a standard suite of questions, which was divided into two sets: primary and secondary. The set of primary questions dealt with the PEOs' overall opinions about Army acquisition and the ways in which the ASSIP could help. The set of secondary questions dealt mainly with specific ASSIP activities and activities in each PEO's office.

Although the interviews were conducted on a confidential basis, the SEI aggregated the results in a non-attributable manner to foster analysis. The results generated by using the BFI method are remarkably consistent with those generated by the PEO interviews. Blanchette presents a detailed discussion of the PEO interviews and results in a special report [Blanchette 05]. 


\section{Method Description}

The BFI method formed the backbone of the ASSIP data-gathering efforts during fiscal year 2003-2004. It offers a rarely seen view of PMOs, largely because PMOs are busy executing their missions. In general, PMOs are "too full up” to stop and take stock. Even though participation in the BFI effort may have been perceived by some as a drain on PMO resources, the PMOs were rewarded with information from a perspective that reflects both breadth and depth. The results identify issues across project management domains, such as accounting and systems, in relation to the software in the system.

\subsection{The BFI Method}

The BFI method employs a series of structured interviews with PMO personnel (similar to many assessment techniques ${ }^{2}$ ), but the focus is on discovery of the effectiveness of the business practices and processes in use in the PMO, rather than on compliance with some standard or model. To provide consistency across the interviews, a list of interview questions was prepared for use by the primary interviewers. The structure of the interview questions reflected that of the CMMI Acquisition Module (CMMI-AM), Version 1.0 [Bernard 04]. Appendix $\mathrm{B}$ of this report contains the interview questions.

The BFI process began by identifying volunteer PMOs that represent each of the PEOs. Final selections were made based on the program's ACAT level and the degree to which the program's mission was of a software-intensive nature. Selected PMOs were then notified and PEO/AAG coordination activities started, including scheduling a week for on-site work, establishing a list of people from the PMO who would participate in interviews, and building the SEI-led team of interviewers. Usually the PMO point of contact and SEI's BFI Team Lead prepared the detailed interview schedules based on how the program office was organized. At least two weeks before the on-site portion of the BFI engagement occurred, the coordination phase was completed by having the PMO point of contact agree to the plan for the engagement.

During the PEO/AAG coordination phase, the AAG members from each PEO received the list of interview questions as read-ahead material. This allowed the PEOs to become familiar with the discussion materials and to support the PMO staffs prior to the BFI interviews. The

2 The basic process for the BFI follows many of the same requirements established for the SCAMPI Class B and Class C methods. You can find additional information on these methods in the handbook Standard CMMI ${ }^{\circledR}$ Appraisal Method for Process Improvement $\left(S C A M P I^{S M}\right)$, Version 1.1: Method Definition Document (CMU/SEI-2001-HB-001) at http://www.sei.cmu.edu/publications/documents/01.reports/01hb001.html. 
point of contact for each PMO also received a copy of the interview questions along with an ASSIP overview brief to help them prepare the PMO staff.

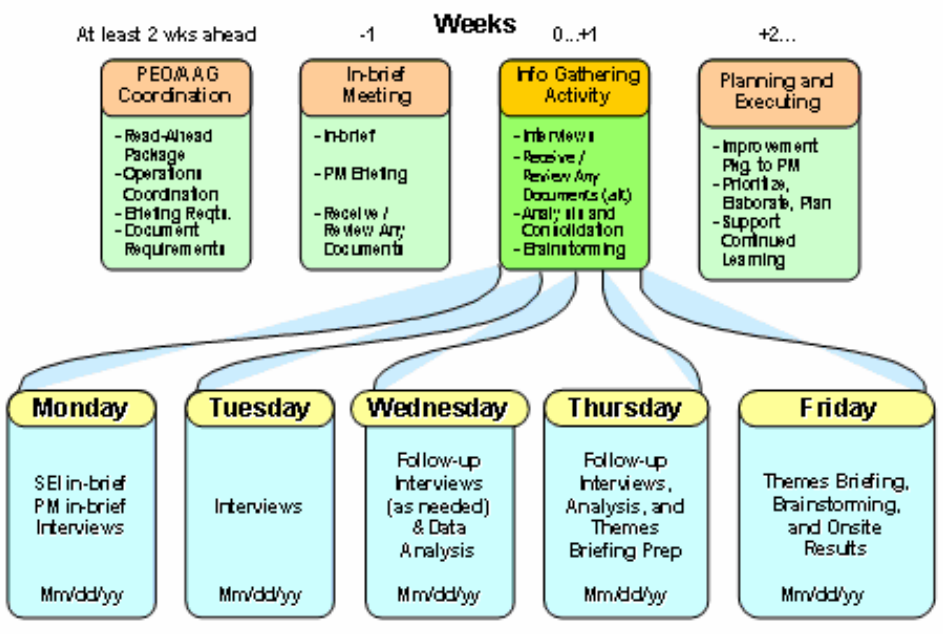

\section{Figure 2: BFI Method Synopsis}

In addition to the read-ahead materials, the PMO could request an in-brief (Phase-1) meeting with the SEI's BFI Team Lead. For PMOs who selected this option, the BFI Team Lead presented the in-brief, addressed questions, and worked with the PM to finalize the on-site interview schedule.

The BFI information-gathering activities took place on-site. The first day of the on-site visit included a presentation about the BFI process and ASSIP from the BFI Team Lead to the PM and PMO staff. The PM or a member of the PMO staff then presented background information about the program including how long the PM has been with the PMO, data about the primary customer/end-user of the program's product, and program progress to date. This presentation also provided insight into the life cycle of the program and some of the challenges it encountered. Following the formal group presentations, one-on-one interviews based on the roles and responsibilities of the PMO staff were conducted.

Interview teams consisted of three to four SEI technical staff members, with one member acting as the primary interviewer and the other team members acting as listeners and recorders. All of the interviews were conducted under the non-attribution, confidentiality guidelines used in other SEI appraisal methods. Under these guidelines, each PMO owns its individual BFI results. However, the SEI maintains of a copy of the results for aggregation and analysis of broad trends. When best practices were discovered during the BFI process, those practices were highlighted in the results with the knowledge and consent of the PMO.

While the goal of the interviews was to discover how Army PMOs conduct their program management functions, interviewers did not interrupt the discussions if they touched on 
broader acquisition issues, which nearly all of the interviews did. Software is but one of many interrelated components of an acquisition program and understanding the whole picture is critical to addressing systemic problems rather than individual symptoms. As issues arose during interviews, the SEI's BFI team encouraged elaboration of the information to better understand the scope of the issue.

After the information-gathering activities of the interviews were completed, the BFI team analyzed the data to determine if common threads were present. When there were findings having a common thread, the information was grouped under a "theme" that reflected the common nature of the comments. Some findings were reported to the PM and PMO staff verbatim in the out-brief to ensure attendees understood the relevance of the results. When recommendations could be made based on the experiences of the PMO or BFI team they were included in the out-brief. The BFI team presented the themes, findings, and recommendations to the PM and PMO staff during the final out-brief. As mentioned earlier, the PMO retains full ownership of the out-brief and determines when and how its contents can be shared.

\subsection{Benefits of the BFI Method}

For their investment in the BFI process, PMOs received immediate and confidential feedback about their current practices and can leverage that information to develop action plans based on their needs. For example, one program used its results to validate its ongoing process improvement initiatives. Another program used its results as the basis for beginning improvement activities. Even some PEOs (the organizational level above the PMOs) have used BFI results to start their own improvement work.

BFI results also provide PMOs with an opportunity to anonymously comment on and influence higher level policies, with the SEI acting as an advocate. In addition, the PMOs also benefit from continued expert consultation through an ongoing relationship with SEI to monitor the successes and shortcomings of their improvement strategies.

BFI results provide a basis from which a number of other possible actions may be taken, because the daily activities and business practices of the program offices are reflected in the information gathered through the interview process. The perceptions of the PMO staff with regard to the external organizational influences are important indicators of how well higher level directives can be interpreted and implemented.

Unlike more robust assessment methods, the BFI method does not require documented support of assertions about business practices. The interview results are taken at face value without additional research into the validity of the assertions. For example, the opinions expressed regarding the Army's Software Blocking policy were not investigated beyond the PMO's viewpoint for the purpose of developing this report. Thus, work done outside of the PMO to "harmonize" and clarify the Software Blocking policy is not reflected in this report. 
Despite these limitations, the BFI results provide a valuable tool for quickly identifying both persistent issues and immediate opportunities for program improvement.

\subsection{Potential for BFI Method Improvements}

As with any attempt to provide meaningful information to decision makers, the integrity of the information is always at issue. This issue is a constant whether the information being conveyed is anecdotal, as is the case with the BFI results, or subject to even more stringent rules, as with statistical approaches. The BFI method belongs to the family of methods such as the Delphi method, ${ }^{3}$ Grounded Theory, ${ }^{4}$ or any of a number of similar informationgathering methods. When applying these methods, the reports of interviewees are the primary means by which construals (i.e., translations or interpretations) of the information are the products of the effort. These methods inherently possess certain risks. The following list outlines the kinds of risks associated with an anecdotal information-gathering method:

- Interviewees may come to the experience with an explicit information-sharing "agenda.”

- Interviewers can "lead” interviewees in eliciting responses.

- To organizations new to process improvement, the level of rigor applied during the BFI process may seem sufficient to approach systemic organizational problems.

- Terms used as the subject of interview questions (e.g., "requirements," "configuration management”) often have important differences of meaning according the interviewees' expertise and context of work. Researchers may not detect these differences.

- Face-to-face interviews cannot assess the extent of a problem, yet the strongly held beliefs and convictions of interviewees can impress interviewers that an issue is (de facto) "important."

- Depending on the structure of interviews, interviewees may be induced to share information according to the desires of their peers or their leadership.

- All extrapolations of solutions derived solely from anecdotal data are at risk of being completely wrong.

The mitigations for these risks include the following:

- Treat solution actions arising from anecdotal information as experimental in nature and small in the scope of their application.

3 The Delphi method has traditionally been a technique aimed at building an agreement, or consensus about an opinion or view, without necessarily having people meet face to face, such as through surveys, questionnaires, emails etc. This technique, if used effectively, can be highly efficient and generate new knowledge [Wikipedia 05a].

4 Grounded theory is a general research method for social sciences developed by the sociologists Barney Glaser and Anselm Strauss [Wikipedia 05b]. For more information, visit http://www.groundedtheory.com/. 
- Use the anecdotal information as a body of "hints" requiring follow-up using more exacting methods of information gathering.

- Cross-reference information gathered with the anecdotal information using more precise means to increase confidence in the integrity of the information (sometimes referred to as triangulation of information).

- Provide clear guidance and training to interviewers.

- Ensure specific ground rules are followed for all interviews.

Thus far, SEI BFI teams and organizations applying the BFI results have followed a few of the stringencies mentioned above as mitigations. However, improvements in training and other aspects of ensuring information integrity are recommended if the BFI method continues to be employed over an extended period of time. Modifications to the method could include the following:

- $\quad$ required BFI Team Lead and interviewer training

- standardized glossary of terms for use by both interviewees and interviewers

- deliberate scoping of the method to limit its use for relatively near-term improvement targets. This would ensure that results from a BFI process would not be applied widely without the application of much more exacting methods of information gathering. 


\section{The BFI Results}

Each of the PMOs expressed a variety of opinions and concerns about the state of Army acquisition. Although they each cited specific problems within their respective domains, they also identified some systemic issues. This report addresses only the systemic issues. In areas where PMOs could identify recommendations for addressing some of the systemic issues, the recommendations are provided in this report. Although BFI results for individual programs remain the property of the respective PMOs, the SEI has aggregated the results in a nonattributable manner to foster analysis. While the SEI maintains the confidentiality of individual respondents, this section of the report includes quotations that punctuate the findings. Note that the SEI BFI team did not attempt to verify the opinions or assertions expressed herein.

The BFI results presented in this report are organized by the themes or common subjects that surfaced across most of the PMOs. In the BFI process, themes represent repeated references to common topics or specific phenomena either within or across programs. Themes are identified by the BFI team during consolidation of the information collected during interviews and presentations. The following sections are based on the findings of the $12 \mathrm{BFI}$ engagements conducted through September 2004. They represent a collection of all of the final onsite briefings provided to the programs and program leadership. Consider each of the themes listed below separately, since each represents a particular comment made by more than three of the PMOs. Upon reviewing the interview responses, several themes emerged:

- risk management processes are not standardized

- acquisition process policy changes have created confusion

- contractor oversight is inconsistent

- staff expertise is mismatched and TSM groups are understaffed

- policies are in constant flux

- career development does not take into account relevant experience

- Integrated Product Teams are not executed effectively

The following sections discuss each of these themes in more detail. The order of discussion is not relevant or significant and readers should not ascribe priority or importance to any of the themes based on sequence. For each theme, there is a discussion of what was found and what could be improved. PMO suggestions for possible improvement are also provided. Under the theme risk management, the results highlight an exemplary implementation of a risk management program. 


\subsection{Theme: Risk Management}

Risk management practices are not standardized and risks are inconsistently and insufficiently tracked, updated, and addressed.

\subsubsection{What Was Found}

Most PMOs apply some form of risk management. Unfortunately, most programs do not evaluate and mitigate program-impacting risks before they become schedule and cost problems. Risk management practices are not standardized and risks are not consistently tracked, updated, and addressed sufficiently. The likelihood of risk repositories being up-to-date and reflective of the actual technical risks for the program is usually very low. In this situation, a PM should expect "surprises" on a regular basis. The environment of fire-fighting in a program office is directly related to some of these surprises cropping up.

One area that any program we contacted did not identify as a risk is the personnel rotation that affects every PMO. Another area of risk, budget cuts and unfunded new work (policy, directives, war, updates to standards, etc.), is regularly realized but very rarely is mitigation or contingency planning conducted.

\subsubsection{What Could Be Improved}

The SEI's BFI team made several improvement recommendations for each program office related to risk management. However, some of the responsibility for improving risk management practices across the DA must be coordinated across all levels of the program structure (DA, PEO, PMO). Improvement recommendations include standardizing the risk management method for the DA, providing tailoring options and associated training for PMOs, providing risk identification and mitigation training for all program stakeholders, and reviewing the identified risks regularly. Risk repositories must be kept up-to-date with associated mitigation and burn-down plans. Regular reviews and communication about program risks should be part of the program monitoring plans. The use of quantitative methods to establish the severity and priority of risks is needed to remove subjectivity with regard to the program risks. The entire risk process then needs to be enforced via oversight processes to assure adherence.

Every PMO should maintain a risk management program and a risk repository that is separate from the contractor's program and risk repository. PMO-specific risks should not be entered into the risk repository for the product. This particular recommendation caused confusion in most program offices.

The risks that are specific to the development, delivery, and sustainment of the software and system product being acquired should be part of a common product-oriented risk repository. The currency and correctness of the data in this repository is the combined responsibility of the program office staff and any contractors that support the development effort. The focus of this information should be on risks to the product. 
Program office risks, which should be tracked and managed separately, include risks like retirement of the program manager, loss of funding due to Congressional actions, and other Army-specific risks that could affect the program office, but may not affect the success of the product.

\subsubsection{An Exemplary Implementation}

In one program office and PEO, we found a particularly robust risk management program. Risk management practices are well documented, supported by consistent training and quantitative evaluation of risks, regularly reviewed with program-level and senior (PEO) management, and information is kept up-to-date with regard to program specific risks. Program risks that should not be viewed by the contractor are separate and tracked in a spreadsheet, since they are a smaller and more tightly controlled group of items. The program risks related to the development of the product are kept in a risk repository that allows shared access by the program office staff, contractors, and senior level management. There is a well-defined structure for initially reporting and evaluating a risk item, establishing the severity and priority levels quantitatively, developing risk mitigation plans, and communicating the status of each risk item. With permission of the program office and PEO, the risk management process of PM-Excalibur and PEO AMMO at Picatinny Arsenal, N.J. is highlighted for reference by other Army program offices.

\subsection{Theme: Acquisition Process - Traditional vs. New Mandates}

The acquisition policy changes over the past five years have created confusion and related difficulties that are exacerbated by operational demands for rapid delivery of early capability.

\subsubsection{What Was Found}

As a result of acquisition policy changes over the past five years, program offices consistently commented on disconnected and poorly communicated acquisition practices. In the context of daily operations at the program office, there is a fundamental conflict between responding to immediate warfighter needs and following the traditional acquisition process. The traditional acquisition process is still used as the basis for overall program planning, funding, and oversight, despite immediate needs for rapid fielding in support of Operation Iraqi Freedom and Operation Enduring Freedom. While the lighter weight acquisition practices required for rapid fielding are welcomed, the removal of levels of guidance causes some confusion and related difficulties. For example, external organizations that must review and approve deliverables at specific milestones are not using a process that fully reflects rapid/early fielding or spiral development methodologies. 


\subsubsection{What Can Be Improved}

Improvement opportunities associated with this theme emphasize the need to balance the policy-driven formal acquisition process with the ability of PMOs to respond quickly to warfighter needs. A single group that harmonizes the policies and processes either for the DA or across the DoD should be identified. This group should also provide support for implementation of the harmonized policies. Programs piloting new initiatives like rapid fielding need the flexibility and explicit authority to "violate" policies that conflict with the pilot effort.

The tension between rapid delivery and formal acquisition processes is also reflected in the way requirements are conveyed to PMOs. In the Army, the TRADOC System Managers (TSMs) represent the user community to the PMO. Some TSMs may also need to adapt their processes to the way warfighter needs are addressed with initiatives such as the Rapid Fielding Initiative, Early Fielding, and so on.

\subsection{Theme: Oversight}

Oversight and monitoring of the contractor's system engineering and management practices are not executed consistently.

\subsubsection{What Was Found}

BFI teams found that the PMOs' oversight and monitoring of systems engineering, software development, and management practices of the responsible organizations is inconsistent. While many of the practices of the PMOs are very good, they are not executed consistently due to lack of documentation and training. This is especially true in cases where the organizations responsible for the engineering and development work are external contractors.

Some program offices use software and systems engineering staffs matrixed from other internal organizations, such as the Research, Development, and Engineering Command (RDEC) software engineering centers (SECs), who provide good management and monitoring of software development practices. Unfortunately, this does not apply to all program offices. This results in inadequate insight into the processes used by the contractors to develop or test the software and integrate the system. Specific aspects of this finding include the following:

- Development documentation and metrics are not always available to the program office.

- PMOs lack the experience and expertise needed to review development documentation and metrics.

- PMOs do not enforce contractors to adhere to software development processes.

- Oversight and management processes within the PMOs are ad hoc, inconsistent, and undocumented.

- No common program monitoring and review processes exist (between the PMOs and contractors and between the prime contractor and subcontractors). 
- PMOs have multiple reporting chains that require similar information to be maintained in different formats. As a result, the amount of time that the program office spends preparing information for oversight is excessive or redundant.

\subsubsection{What Can Be Improved}

PMs should demand sufficient staff who possess the software and systems engineering expertise needed to define the required metrics for the program and objectively evaluate software development processes. Staffs should have training and development experience. Each PMO should implement an oversight and management process to coordinate and control internal administrative information (IPT status, metrics, schedules, etc.). This process should include defining and documenting current practices (IPT start-up, mentoring, document review, requirements writing and verification, etc.). After processes are documented, PMOs should establish repositories for storing metrics, lessons learned, templates, historical data, and so on. Regularly reviewing the information in the repository allows the PMO to reuse the information that was successful and improve the areas that need attention.

Across the Army, there is a need to develop training and mentoring programs for new PMs and mechanisms to share best practices across PMs.

\subsection{Theme: Staff Skills}

Program management offices do not have personnel with specialized skills to respond to all of the demands of their jobs. In addition, TSM groups are understaffed.

\subsubsection{What Was Found}

PMOs are not sufficiently staffed with personnel who have the appropriate specialized skills to respond to all of the demands of their jobs. In addition to PMO staffing issues, TSM groups are often understaffed and struggle to represent users effectively. Key skills are being lost from the both TSM groups and Army Acquisition Corps, making continuity of end-user knowledge and management of contractors difficult. Less experienced staffs do not have the backgrounds needed to effectively monitor contractors in a less restrictive contracting environment. Existing staffs cannot adequately evaluate reuse claims, requirements documentation, architecture, detailed design, progress at formal technical reviews, or articulate the software risks on the program. In addition, there is not enough software expertise available to manage programs adequately.

Some program offices do an excellent job of leveraging external assets available to them, like SECs, to meet program needs. In other program offices, staffing limitations force PMs to use support contractors or their prime contractor for program office support. While support contractors have been integrated successfully into many PMOs (especially when the support contractors retired from the organization for which they are now working), not all of the program offices have access to or funding for support contractors. 


\subsubsection{What Can Be Improved}

The SEI BFI team recommends that PMOs investigate existing program-level and manager practices and lessons learned and take advantage of the services provided by Army organizations like the SECs, Defense Contract Management Agency (DCMA), and the Cost and Economic Analysis Center (CEAC). The CEAC is one of the groups that provide essential expertise to the program offices. The measurement expertise of the CEAC group should be consistently employed to guide programs, especially to help programs support estimates with historical data. Use the knowledge on existing programs to build a forum for PMs to discuss program management issues and solutions. Consider using subject matter experts from organizations like Federally Funded Research and Development Centers (FFRDCs) like MITRE and the SEI.

There also needs to be a better balance between the number of people who work for the government and those contracted to support the PMO, with the preferred emphasis on government staff (military and/or civilian). More than one PM emphasized the importance of ensuring that the warfighter mission stays at the top of the program's priority list. To this PM, the only way to keep the priority of the warfighter mission at the correct level is to make sure that the PM or Deputy PM is a "green suiter" (Army officer). The insistence to use Army military or civilian personnel also reflects the need for people who have both domain-specific skills and knowledge of the Army. One PM specifically cited non-military staff not understanding the culture and the associated inability to address the hierarchy of the Army as a problem area. On the other hand, the continuity that PMOs find through the use of nonmilitary deputies or technical directors is also needed to ensure that program and contract knowledge is bridged when PMs leave for their next military assignment or retire.

\subsubsection{Suggested Improvement}

The issue of command continuity generated a few ideas for improvement among participants.

- Develop a "scorecard" for the life of a program, so that a PM continues to bear some responsibility for program success even after moving to a new assignment.

- Make assignment durations flexible, so that a PM remains in a position until achieving some measurable accomplishment.

- Shorten approval cycles by restructuring the leadership group to ensure only decision makers are in the approval loop.

\subsection{Theme: Policy}

Program management offices perceive OSD and Department of the Army policy and directives as being in constant flux, making it difficult to identify or develop policy interpretation expertise. 


\subsubsection{What Was Found}

Program offices report that they perceive policies and regulations as being in constant flux, making it difficult to identify or develop policy interpretation expertise. It seems to the PMOs that the current practice is to develop policies in stovepipes. When a policy or directive reaches the PMO, there is little or no guidance for implementation. In many cases, policy changes are mandated without funding or schedule adjustments being made for program implementation. In some cases, the policy implementation is retroactive to the beginning phases of a program. This may force a program to redo months or years of work. The application of new or changed policies for ongoing programs affects the entire program profile (funding, requirements, schedule, resources, etc.).

Interviewees often spoke about the need for their questions about policy and regulations to be answered in a consistent, timely, and accurate fashion. For example, Joint Technical Architecture-Army (JTA-A) and Software Blocking documentation is not comprehensive and should be replaced with a more thorough, but concise standard. Further, particular elements of the JTA-A and the Software Blocking policy appear to be at odds with each other. In addition, following the JTA-A forces system architectures to be more restricted and closed compared to pure JTA implementations. Their superiors or their peers do no communicate key knowledge about JTA-A and Software Blocking issues effectively to the PMOs.

In other cases, it is unclear to program offices which version of the policies to use. Even the documents considered to be the "definitive source" of the policy are missing appropriate date and version numbers to indicate currency. This lack of configuration control causes implementation delays and may require PMOs to perform multiple reviews to determine which documents are complete and correct.

\subsubsection{What Can Be Improved}

Interviewees suggest that there needs to be a process by which policies and regulations are analyzed for impact on PMOs before they are implemented. An example of this would include getting different programs to agreement on standards for the types and levels of interoperability needed between them. This ensures that it is then possible to assess whether or not interoperability is achieved.

The authors of policies and regulations should be accountable for addressing implementation and interpretation issues. The current resources available to programs to address such questions are viewed as ineffective. Another suggestion that surfaces frequently is that policy changes should be supported by training, consistent and knowledgeable support, interpretation, and enforcement. Along these same lines, new policies should include examples (operational examples of implemented policy) where applicable.

Additionally, the Army Acquisition Policy (AR 70-1) is the Army's top-level acquisition policy. However, the systems and software policies specified in this document do not pertain to IT organizations that develop systems for the Army. Many "new” systems products being 
developed use commercial off-the-shelf (COTS) products and commercial IT-oriented practices that fall outside of the "weapon systems" orientation of Army policies. This gap needs to be addressed as part of the overall interoperability and systems architecture policy solution for the Army.

\subsubsection{Suggested Improvement}

A seemingly simple suggestion from one PMO is to have OUSD(AT\&L) policy writers coordinate with service counterparts to provide consistent acquisition policies throughout DoD.

\subsection{Theme: Career Development}

Program management certification does not sufficiently recognize the value of developmental, operational, TSM, DA, or OSD assignments.

\subsubsection{What We Found}

DoD program management certification standards do not recognize practical experience as a contributor to a PM's success. Becoming an effective program or product manager requires having the right developmental assignments. PMs who had operational, OSD, Pentagon, or TSM assignments prior to taking on PM responsibilities appear to be more successful.

\subsubsection{What Can Be Improved}

Balance staff rotations at senior levels with changes to the overall Army mission and needs. Prospective PMs appear to benefit from spending an "internship" period in ASA(ALT), DA, or OSD offices. In addition, broad exposure to the requirements development process was cited as beneficial to prospective PMs. Interviewees also felt that TRADOC staff should participate in an internship at a PMO. When these assignments are not possible, PMs and Army civilians with Army staff experience and technical and domain program experience should mentor acquisition corps members who plan to become PMs.

\subsubsection{Suggested Improvement}

Interviewees identified several ideas for improving the PM selection process:

- Allow PM candidates to bid for positions for which their qualifications are appropriate. Make an applicant's preference statement meaningful by giving it due consideration. Focus on getting the right person for the job.

- Let candidates work together to select the jobs they want (and for which they possess the right qualifications) and negotiate with each other to determine final assignments.

- Do not assign "take it or leave it” positions, which force too many PMs to end their Army careers. 


\subsection{Theme: Integrated Product Teams}

Some programs do not execute Integrated Product Teams effectively.

\subsubsection{What Was Found}

The good news in this area is that all programs use IPTs or working groups to develop work products and manage programs. Most of these teams facilitate good communications between members of the development team and PMO staff.

On the other hand, some IPTs are not executed in a manner consistent with the DoD's vision of an Integrated Product and Process Development approach. For example, in some IPTs, not all disciplines are represented, no common set of processes is defined, there is no shared vision of the product objectives, or there are no clearly defined roles and responsibilities. This finding reflects the danger of implementing a mandate without the associated training and tools.

\subsubsection{What Can Be Improved}

Strengthen IPT practices by ensuring consistent and up-to-date training for team members and managers. Produce charters for each team that defines team membership, the vision or mission of each team, roles that each team must perform, responsibilities, reporting and escalation processes, and how improvements will be made to the products and team structure.

Do not force PMOs to adopt an IPT approach. When an IPT approach is not appropriate for the work or business structure, allow the use of working groups or other organizational structures. 


\section{Next Steps}

This report documents the results of the BFI activities conducted as part of ASSIP datagathering efforts. BFI activities are one of several efforts geared toward creating an accurate picture of processes supporting Army software and systems acquisition. The BFI interviews of PMO staffs operate in conjunction with (but do not depend on) other activities such as the PEO survey and the PEO interviews described in Section 1.1 of this report. Our goal is to develop an "accurate picture" for the purposes of making high-leverage changes that benefit individual programs and Army acquisition in general.

\subsection{Analyzing the Findings}

One of the most important next steps is to analyze the BFI results, along with the results of the other data-gathering efforts discussed in Section 1.1, to discover which problems are the most troublesome systemically. Identifying those problems reveals potential high-impact improvement opportunities.

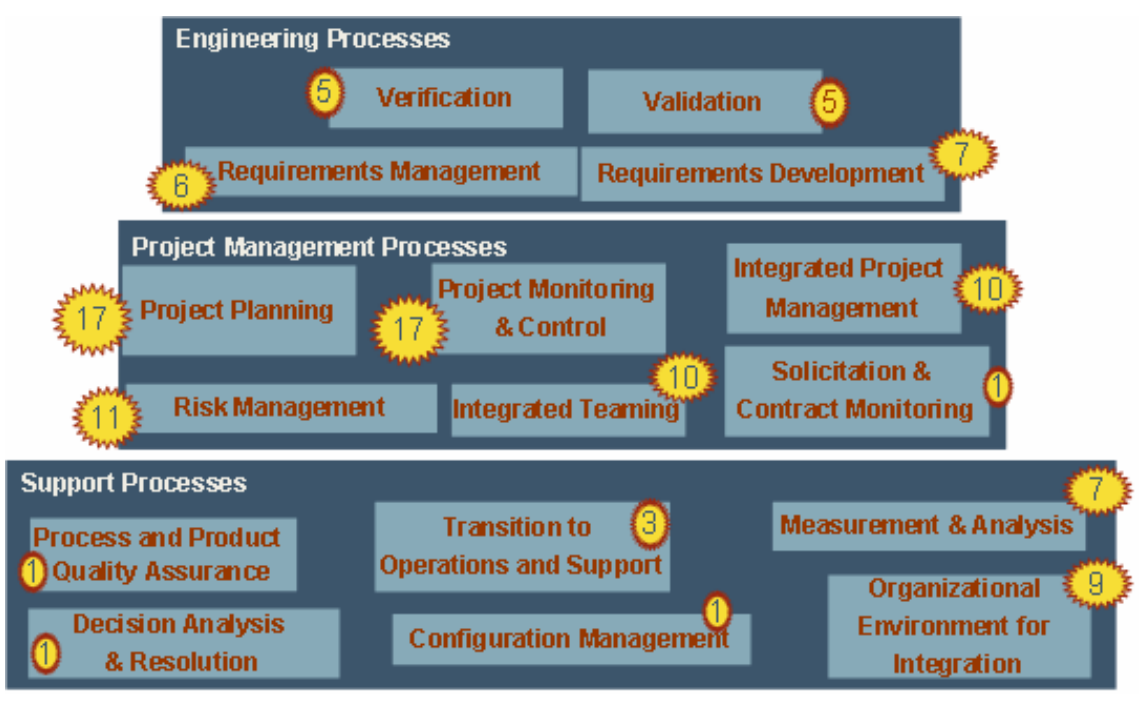

Figure 3: Analysis of BFI Findings

Figure 3 depicts the raw findings from the 12 PMOs that participated in the BFI process. The numbers of findings are denoted by the numeric values, which are categorized according to the process areas identified in the Capability Maturity Model Integration Acquisition Module (CMMI-AM), Version 1.0 [Bernard 04]. As might be expected for PMOs, this analysis shows that the findings are overwhelmingly in the Project Planning and Project Monitoring and 
Control process areas. Focusing improvement efforts in these areas is likely to result in a

high return on investment for PMOs.

\subsection{Using the Findings}

The results of the BFI activities suggest that there are several avenues of pursuit for improving Army acquisition, especially as it relates to software-intensive systems. While each program office had concerns specifically related to its own domain, a number of common issues arose. Common issues revolved around skills and training of PMs, policy and its application, the acquisition organization and its workings, and the use of processes and their effects.

The AAG updates its ASSIP Strategic Software Improvement Master Plan (SSIMP) each fiscal year. PEOs approve the SSIMP, which is then signed by the MILDEP. The BFI results have helped to guide the initiatives included in the FY06 SSIMP, which defines specific tasks to alleviate some of the perceived problems in SIS acquisition. Tasks are organized within initiatives in the following areas:

- Acquisition Process Improvement

- Education

- Measurement

- Architecture

- System of Systems Integration

- Management, Analysis, and Strategic Planning

As the ASSIP continues to promote acquisition process improvement, the SEI will revisit the BFI results to determine how process changes have affected Army SIS acquisition. The SEI will also broaden the pool of interviewees to include other senior stakeholders in Army acquisition.

\subsection{Issues Related to Information Processing}

As discussed in Section 2, the BFI method is a non-parametric form of information gathering. This implies that the opinions solicited during interviews may require further investigation to substantiate the accuracy and character of the information prior to taking actions towards improvement.

As programs determine courses of action, it may be necessary to conduct more focused and refined information-gathering efforts that have greater quantitative precision in order to evaluate improvement options. One alternative for collecting detailed information is the use of model-based appraisals. A model-based appraisal provides more precision and a method for benchmarking the program against an industry and government measurement mechanism. 
Often, the use of metrics can help to discern problems that may be more pressing but less visible. 


\section{Summary}

Studies on the return on investment for process improvement efforts are hopeful. By using disciplined methods of intervention, identifying opportunities for improvement, and defining clear improvement objectives, programs can achieve high rewards as they seek to improve processes [Capell 04]. Participating in BFI activities is a good starting point for a program's improvement efforts.

Application of the BFI method fills a gap in information-gathering methods for the ASSIP. While the BFI method is not without flaws, it provides a flexible, readily applicable means of acquiring information quickly. Results from the compilation of all of the BFI engagements conducted to date show that there are opportunities for improvement within the DA. The results also show that important information exists within the program offices that form the foundation for those improvements.

While the PMOs expressed a great many concerns and frustrations with the current state of Army SIS acquisition, they also offered some thought-provoking ideas for improvement. More work remains to understand the root causes of problems within SIS acquisition and tackling the problems requires a long-term commitment. The ASSIP provides the impetus and infrastructure to identify these issues and formulate strategic approaches to address them. 


\section{Feedback}

Through its Acquisition Support Program, the SEI is working to help improve SIS acquisition across the U.S. government. Consequently, the SEI is very interested in hearing how the perspectives presented here compare with those of senior acquisition officials in the other services, defense agencies, and other federal agencies.

Please send questions or comments about this report to Kristi L. Keeler (kkeeler@sei.cmu.edu). 


\section{Appendix A Acronyms and Abbreviations}

The alphabetical listing below contains all acronyms, abbreviations, and their meanings as used in this report.

\begin{tabular}{|c|c|}
\hline AAG & ASSIP Action Group \\
\hline ACAT & Acquisition Category \\
\hline Ammo & Ammunition \\
\hline ASA(ALT) & $\begin{array}{l}\text { Assistant Secretary of the Army for Acquisition, Logistics, and } \\
\text { Technology }\end{array}$ \\
\hline ASSIP & Army Strategic Software Improvement Program \\
\hline BFI & Benchmarking for Improvement \\
\hline CEAC & Cost and Economic Analysis Center \\
\hline $\mathrm{CM}$ & Configuration Management \\
\hline CMM & Capability Maturity Model \\
\hline CMMI & Capability Maturity Model Integration \\
\hline CMU & Carnegie Mellon University \\
\hline COTS & Commercial Off-the-Shelf \\
\hline C/PAR & Corrective/Preventive Action Report \\
\hline DA & Department of the Army \\
\hline DAU & Defense Acquisition University \\
\hline DCMA & Defense Contract Management Agency \\
\hline DoD & Department of Defense \\
\hline FFRDC & Federally Funded Research and Development Center \\
\hline FY & Fiscal Year \\
\hline
\end{tabular}




\begin{tabular}{|c|c|}
\hline HQDA & Headquarters, Department of the Army \\
\hline IPT & Integrated Product Team \\
\hline JTA-A & Joint Technical Architecture-Army \\
\hline MILDEP & Military Deputy \\
\hline OSD & Office of the Secretary of Defense \\
\hline OUSD(AT\&L) & $\begin{array}{l}\text { Office of the Undersecretary of Defense for Acquisition, Technology, and } \\
\text { Logistics }\end{array}$ \\
\hline PEO & $\begin{array}{l}\text { Program Executive Officer } \\
\text { Program Executive Office }\end{array}$ \\
\hline PM & $\begin{array}{l}\text { Project Manager } \\
\text { Program Manager }\end{array}$ \\
\hline & Product Manager \\
\hline PMO & Program Management Office \\
\hline QFD & Quality Function Deployment \\
\hline RDEC & Research, Development, and Engineering Command \\
\hline SCAMPI & Standard CMMI Appraisal Method for Process Improvement \\
\hline SEC & $\begin{array}{l}\text { Software Engineering Center } \\
\text { Systems Engineering Center }\end{array}$ \\
\hline SEI & Software Engineering Institute \\
\hline SIS & Software-Intensive Systems \\
\hline SR & Special Report \\
\hline SSG & Senior Steering Group \\
\hline SSIMP & Strategic Software Improvement Master Plan \\
\hline TRADOC & Training and Doctrine Command \\
\hline TSM & TRADOC System Manager \\
\hline
\end{tabular}




\section{Appendix B Benchmarking for Improvement Interview Questions}

This appendix documents the questions and comments used for conducting interviews of Army software-intensive system acquisition stakeholders, subject matter experts, and program members both within the program participating in the BFI process and in associated organizations.

The objective of the interview questions is to

- determine what topics interviewees believe are important to cover for benchmarking

- determine the objective view of the interviewee regarding priority problems, risks, issues, opportunities and best practices most important to the program

- obtain interviewees' suggestions as to the kind of benchmarks they think program practices should be evaluated against

\section{Setting the Stage for Questions}

This work is part of an effort to produce an Army-wide software intensive system Acquisition Improvement Master Plan to identify problem areas and opportunities where significant improvement can take place and to work with selected programs to provide exemplars on how innovations have been or could be achieved.

Our first step is to get to know the program we are working with through interviewing a cross section of program members and stakeholders.

We will start each interview by asking each interviewee some very general and open-ended questions, proceed with follow-up questions for clarification and elaboration and finally, and if there is time, ask questions on various topics in software intensive system acquisition that have been identified by previous investigation as areas of interest. 


\section{Interview Questions}

\section{General}

Q1.

Experience, Role, and

Areas of Work

Comments

\section{Could you please describe your experience with the program, what your role is, and what areas of work you think are exem- plary and/or in need of improvement.}

There are various ways that the respondent might have knowledge of the program and it would be helpful to know how this experience was acquired. Examples include:

- Previous work as part of a similar acquisition configuration management and testing program or system of systems program; if so, what was their role? (PEO? PM? Team member? In the overall system program, in one of the systems programs?)

- Policy-maker covering acquisition configuration management and testing programs and/or system of systems programs

- Research and/or collaboration (in the acquisition configuration management and testing and/or interoperability arena)

- A developer who worked for an acquirer and has knowledge of acquisition from the configuration management and testing and/or interoperability perspective

The purpose of Q1 is to address these issues and understand the perspective and context from which the respondent is speaking.

- Given those experiences, what were the primary problems you encountered? Please provide the context for each problem that is described.

- What were the key factors that contributed to successes in your previous acquisition work? Please provide the context for each success that is described.

- The term "key factors" can be anything including policy, procedure, management, etc.

- If you could change anything with respect to the program, what would it be? 


\section{Questions Based on the CMMI Acquisition Module (CMMI-AM)}

Questions Q2.1-Q2.16 are based on the CMMI Acquisition Module (CMMI-AM), Version 1.0. Figure 4 contains the process areas in the CMMI Acquisition Module. These process areas serve as the basis for forming questions exploring potential sources of "best practices" in and across acquisition programs. With a clear goal, or "picture of success," a program can identify a wide range of enablers and/or obstacles to achieving their goal using the process areas as a starting point during the interview sessions. Programs that share similar goals might benefit from emulating practices that have been found to be successful or that successfully address similar difficulties.

The execution and institutionalization of a practice may indicate a candidate best or exemplary practice. For example, use of integrated product teaming to address system of systems program management may indicate a whole host of candidate best or exemplary practices that may be applicable in other program contexts. Careful documentation and/or refinement of the practice would not only help the given program but other programs as well.

On the other hand, the lack of a practice, or insufficiency in performing a practice could indicate an area for which an improvement goal needs to be set and steps taken toward achieving it. For example, if a program does not trace user requirements from user capability statements or operational needs down to the product components that implement those capabilities or needs, this insufficiency should cause concern about the program's ability to verify or validate the system to their user's satisfaction. Addressing this insufficiency would be beneficial to the program. Documenting the insufficiency and the steps being taken to address it might also be useful to other programs that may be facing the same problem.

Once enough descriptions of exemplary practices have been generated, candidate best practice areas will emerge. They can become the basis for improvement planning efforts across the Army.

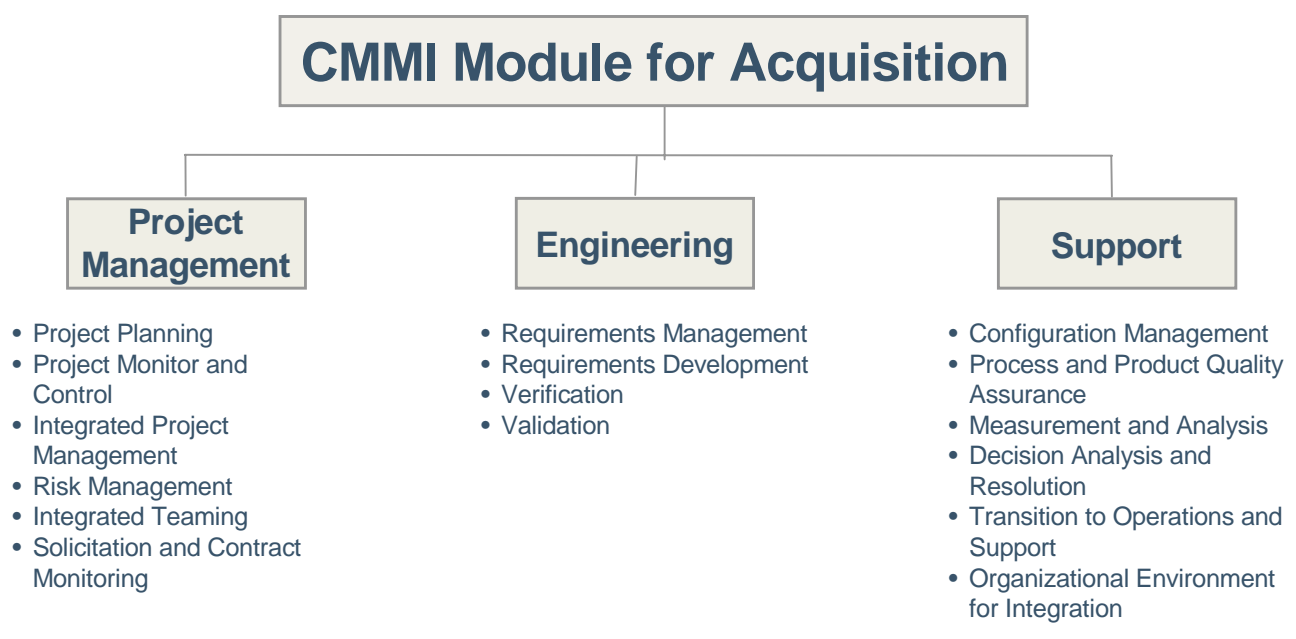

Figure 4: CMMI-AM Process Areas 
Q2.1

Program Planning

Probing Questions

CMMI Practices
How does your program establish and maintain plans that define the program activities?

- How does your program establish the planning parameters (e.g., guidelines and constraints) for estimating effort and cost of its development activities? Is historical data used?

- How does your program establish and maintain its plans?

- How does your program obtain commitments to the program plan? How are these maintained?

- How does your program ensure that program planning is institutionalized as a managed process?

- How does your program perform replanning?

- How does your program plan for the identification and analysis of risk?

Does the program perform any of the following practices? Does the program perform any particularly well? Are their some the program needs or wants to improve?

- Estimate the Scope of the Program

- Establish Estimates of Program Attributes

- Define Program Life Cycle

- Determine Estimates of Effort and Cost

- Establish the Budget and Schedule

- Identify Program Risks

- Plan for Data Management

- Plan for Program Resources

- Plan for Needed Knowledge and Skills

- Plan Stakeholder Involvement

- Establish the Program Plan

- Review Subordinate Plans

- Reconcile Work and Resource Levels

- Obtain Plan Commitment 
Additional Topics

Potential sources of exemplary practices, difficulties, or lacks

Project plans:

- Acquisition Strategy

Transition, etc.

口 Estimation models/results/BOE

$\square$ Evidence of adequate resources and tools

- Project schedules and/or dependencies

$\square$ Management training for planning

口 People assigned responsibility and trained

口 Risk identification/analysis

口 Task planning

$\square$ Coordinate with stakeholders

$\square$ WBS 
Q2.2

Project Monitoring and Control

Probing Questions

CMMI Practices

Additional Topics
How does your program establish and maintain adequate visibility into the program's progress so that corrective actions can be taken when there are significant deviations from the plan?

- How does your program track actual performance of the program against plans?

- How does your program plan for and take corrective actions when the program's performance or results deviate significantly from the plan?

- How does your program ensure that program monitoring and control is institutionalized as a managed process?

- How does your program monitor and record risks and risk activities?

- Does your program revise the program plan to reflect accomplishments, progress, changes, and corrective actions as appropriate?

Does the program perform any of the following practices? Does the program perform any particularly well? Are their some the program needs or wants to improve?

- Monitor Project Planning Parameters

- Monitor Commitments

- Monitor Project Risks

- Monitor Data Management

- Monitor Stakeholder Interactions

- Conduct Progress Reviews

- Conduct Milestone Reviews

- Analyze Issues

- Take Corrective Actions

- Manage Corrective Actions

Potential sources of exemplary practices, difficulties, or lacks

Revised program plans

Evidence of adequate resources and tools

Record of critical facility usage

Status reports

Action items

People assigned responsibility and trained

Records of commitment reviews

口 Corrective action plan

- Documented program and/or milestone reviews 
Q2.3

Integrated Program

Management

Probing Questions

\section{CMMI Practices}


- Determine Integrated Team Structure for the Project

- Develop Preliminary Distribution of Requirements to Integrated Teams

- Establish Integrated Teams

Additional Topics

Q2.4

Risk Management

Probing Questions
Potential sources of exemplary practices, difficulties, or lacks

Tailored process

Revised plans or commitments

Conflict resolution process

口 Life cycle model

Documented internal and external commitments

Joint recommendations on technical issues

action item databases

口 Schedules for collaborative technical activities

IPTs

How does your program identify potential problems before they occur, so that risk handling activities may be planned and invoked as needed across the life cycle to mitigate adverse impacts on achieving objectives?

- How does your program define the requirements and strategy for risk management?

- How does your program determine risk sources and categories?

- How does your program address risks in order to mitigate adverse impacts on achieving objectives?

- How does your program ensure that risk management is institutionalized as a defined process?

- How does your program identify risk?

- Does your program assess the likelihood and consequence of each risk? What is the process?

- How does your program monitor the status of each risk item?

CMMI Practices

Does the program perform any of the following practices? Does the program perform any particularly well? Are their some the program needs or wants to improve?

- Determine Risk Sources and Categories

- Define Risk Parameters

- Establish a Risk Management Strategy

- Identify Risks 
- Evaluate, Classify, and Prioritize Risks

- Develop Risk Mitigation Plans

- Implement Risk Mitigation Plans

Additional Topics

Q2.5

Integrated Teaming

Probing Questions

\section{CMMI Practices}

Potential sources of exemplary practices, difficulties, or lacks

Risk management and mitigation plans

Risk list

$\square$ Risk rating or potential

$\square$ Contingency plans

- Risk prioritization

口 Opportunity management

How does your program form and sustain integrated teams for the development of work products?

- How does your program establish team tasks and resource needs and select team members?

- How does your program govern the activities of the team?

- Do integrated teams have the right mix of skills and resources to function effectively?

- Do team members all share a common picture of success?

- Are team activities, responsibilities, and tasks well defined and understood?

- Are the boundaries and communication paths between teams well understood?

Does the program perform any of the following practices? Does the program perform any particularly well? Are their some the program needs or wants to improve?

- Identify Team Tasks

- Identify Needed Knowledge and Skills

- Assign Appropriate Team Members

- Establish a Shared Vision

- Establish a Team Charter

- Define Roles and Responsibilities

- Establish Operating Procedures

- Collaborate Among Interfacing Teams 
Additional Topics

Q2.6

Solicitation and

Contract Monitoring

Probing Questions
Potential sources of exemplary practices, difficulties, or lacks

Team charter

Representation by disciplines

Clear, written agreements and commitments

Clear leader in charge

Clear tasks and deliverables

Results

How does your program prepare a solicitation package that identifies the needs of a particular acquisition, select a supplier who is best capable of satisfying those needs, and provide leadership throughout the life of the acquisition to ensure those needs are met?

- How does the program prepare to conduct the solicitation?

- How does the program select suppliers based on the solicitation package?

- How does your program issue contracts based on the needs of the acquisition and the suppliers' proposed approaches?

- How does your program coordinate with suppliers to ensure the contract is executed properly?

- How do you ensure the solicitation complies with the applicable federal, department, and service acquisition regulations and policies?

- How do you address issues appropriate to the system domain or acquisition environment (e.g., supplier process evaluations, operational safety suitability and effectiveness, safety, certifications, architecture evaluations, interoperability)?

- How have you negotiated and incorporated into the agreement how integrated teams are formed and team membership is established? 
CMMI Practices

Additional Topics
Does the program perform any of the following practices? Does the program perform any particularly well? Are their some the program needs or wants to improve?

- Designate a Selection Official

- Establish a Solicitation Package and Evaluation Criteria

- Establish Cost and Schedule Estimates

- Validate the Solicitation Package

- Evaluate Proposals

- Use Evaluation Results to Select Suppliers

- Establish an Understanding of the Contract and Proposed Approach

- Establish Communications Processes and Procedures

- Monitor Selected Supplier Processes

- Evaluate Selected Supplier Work Products

- Revise the Supplier Agreement or Relationship

Potential sources of exemplary practices, difficulties, or lacks

- Solicitation package

口 Source selection activities

$\square$ Suppliers proposed approaches

$\square$ Contractual agreements

$\square$ Negotiation processes

口 Evaluation criteria

a Communication strategies

$\square$ Contract monitoring approaches

- Contractual changes 
Q2.7

Configuration

Management

Probing Questions

CMMI Practices

Additional Topics
How does your program establish and maintain the integrity of work products using configuration identification, configuration control, configuration status accounting, and configuration audits?

- How does your program establish and maintain baselines of identified work products?

- How does your program track and control changes to the work products under CM (configuration management)?

- How does your program ensure the integrity of the baselines?

- How does your program ensure that configuration management is institutionalized as a managed process?

- What procedures, tools, and media has your program established for CM/SCM?

- How does your program report CM status and what audits do you perform?

Does the program perform any of the following practices? Does the program perform any particularly well? Are their some the program needs or wants to improve?

- Identify Configuration Items

- Establish a Configuration Management System

- Create or Release Baselines

- $\quad$ Track Changes

- Control Changes

- Establish Configuration Management Records

- Perform Configuration Audits

Potential sources of exemplary practices, difficulties, or lacks

Controlled artifacts

CM/Configuration Management Plan

- Configuration management status reports

$\square$ Revision history of configured items

- CM responsibility assigned

- Change requests and/or metrics

C CCB minutes

C CM tool training 
Q2.8

Process and Product

QA

Probing Questions

CMMI Practices

Additional Topics
How does your program provide its staff and management with objective insight into the processes and associated work products?

- How does your program objectively verify the adherence of work products, and services to applicable process descriptions, standards, and products?

- How does your program ensure that identified non-compliance issues are escalated as necessary for resolution?

- How does your program ensure that process and product quality assurance is institutionalized as a managed process.

- What activities are defined in your quality plan? Are they being performed?

- How does your program periodically report results of process and product quality assurance to those affected?

- Are program personnel informed of quality review/audit results?

Does the program perform any of the following practices? Does the program perform any particularly well? Are their some the program needs or wants to improve?

- Objectively Evaluate Processes

- Objectively Evaluate Work Products and Services

- Communicate and Ensure Resolution of Noncompliance Issues

- Establish Records

Potential sources of exemplary practices, difficulties, or lacks

Process \& Product Quality Assurance Plan

esponsibility assigned

? Training provided

$\square$ Audit records and reports

$\square$ Results/minutes of quality reviews

口 Reporting mechanisms

口 Corrective/preventive action reports (C/PARs) 
Q2.9

Measurement and

Analysis

Probing Questions

CMMI Practices

Additional Topics
How does your program develop and sustain a measurement capability that supports management information needs?

- How does your program ensure that measurement objectives and practices are aligned with established information needs and objectives?

- How does your program ensure that measurement results that address information needs are available?

- How does your program ensure that Measurement and Analysis is institutionalized as a managed process?

- What data has your program collected and stored?

- What analysis and interpretation have your program performed?

- What training is provided to your program to support measurement collection and analysis?

Does the program perform any of the following practices? Does the program perform any particularly well? Are their some the program needs or wants to improve?

- Establish Measurement Objectives

- Specify Measures

- Specify Data Collection and Storage Procedures

- Specify Analysis Procedures

- Collect Measurement Data

- Analyze Measurement Data

- Store Data and Results

- Communicate Results

Potential sources of exemplary practices, difficulties, or lacks

Measurement plans and objectives

Evidence of adequate resources and tools

People assigned responsibility and trained

Measures databases

Results of data integrity tests

Data collection, storage procedures and/or tools

Analysis definitions, procedures and/or tools

- Analysis reports, draft reports, presentations

口 Collected \& derived measurement data sets 
Q2.10

Decision Analysis and

Resolution

Probing Questions

\section{CMMI Practices}

Additional Topics
How does your program establish structured decision making techniques and criteria for use in evaluating identified alternatives?

- How does your program establish, use, and evaluate alternatives when making decisions?

- How does your program establish criteria for evaluating alternative solutions to selected issues?

- How does your program ensure that decision analysis and resolution is institutionalized as a defined process

- How does your program elicit alternative solutions to risks/issues?

- How does your program evaluate and document assumptions?

- How does your program involve the stakeholders in the selection process

Does the program perform any of the following practices? Does the program perform any particularly well? Are their some the program needs or wants to improve?

- Establish and Use Guidelines for Decision Analysis

- Select Evaluation Technique

- Establish Evaluation Criteria

- Identify Proposed Alternatives

- Evaluate Alternative Solutions

- Select Solutions

Potential sources of exemplary practices, difficulties, or lacks

Trade studies

Q Quality Function Deployment (QFD)

口 Criteria weights

Delphi method

$\square$ Group techniques 
Q2.11

Transition to

Operations and

Support

Probing Questions

CMMI Practices

Additional Topics
How does your program provide for the transition of the product to the end user and the eventual support organization and accommodate lifecycle evolution?

- How does your program prepare for transition to operations and support?

- How does your program ensure acquired products are transitioned to operations and support based on transition criteria?

- Who is responsible for maintaining the system post deployment and how do they participate on the program?

- Who is the user representative and how do they participate on the program?

- How will major enhancements be handled and who is responsible for providing the additional capability?

Does the program perform any of the following practices? Does the program perform any particularly well? Are their some the program needs or wants to improve?

- Establish a Transition Strategy

- Establish Product Transition Plans

- Establish Operations and Support Training Requirements

- Establish Lifecycle Resource Requirements

- Identify Support Responsibility

- Establish Enhancement Criteria

- Establish Transition Criteria

- Evaluate Product Readiness

- Evaluate Personnel Readiness

- Analyze Results and Take Action

Potential sources of exemplary practices, difficulties, or lacks

Roles and responsibilities

口 Stakeholder involvement

Transition strategies and plans

Availability of training

Access to maintenance tools and environments

Access to simulators and integration facilities

Capability of potential support organization

Operational impacts due to new system 
Q2.12

Organizational

Environment for

Integration

Probing Questions

CMMI Practices

Additional Topics
How does your organization provide an Integrated Process and Product Development infrastructure and manage people for integration across disciplines?

- How does your organization provide the infrastructure to allow multi-disciplinary teams to successfully function?

- How does your organization the provide management mechanisms to allow multi-disciplinary teams to succeed?

- Does management provide special collaboration tools to allow cross-functional teams to work as a virtual team?

- How are issues and risks identified and addressed within the teams?

- How does the organization establish a shared vision across teams?

Does the program perform any of the following practices? Does the program perform any particularly well? Are their some the program needs or wants to improve?

- Establish the Organization's Shared Vision

- Establish an Integrated Work Environment

- Identify IPPD-Unique Skill Requirements

- Establish Leadership Mechanisms

- Establish Incentives for Integration

- Establish Incentives to Balance Team and Home Organization Responsibilities

Potential sources of exemplary practices, difficulties, or lacks

Collaboration tools

Clearly defined roles and responsibilities

口 Team leadership

Training on working in multi-discipline teams

Encouragement and reward systems for teaming

$\square$ Workload balancing 
Q2.13

Requirements

Management

Probing Questions

CMMI Practices

Additional Topics
How does your program manage the requirements of the program's product, and keep the program's plans and work products consistent with them?

- How are requirements managed so that they accurately reflect the programs plans and products?

- How does your program ensure that requirements management is institutionalized as a managed process?

- How does your program maintain requirements traceability?

- How does your program analyze requirements quality?

- How does your program track work effort against requirements?

Does the program perform any of the following practices? Does the program perform any particularly well? Are their some the program needs or wants to improve?

- Obtain Understanding of Requirements

- Obtain Commitment to Requirements

- Manage Requirement Changes

- Maintain Bi-Directional Traceability of Requirements

- Identify Inconsistencies between Project Work and Requirements

Potential sources of exemplary practices, difficulties, or lacks

Requirements traceability matrix

Requirements management tool, database

Requirements issues and/or action items

Results/minutes of requirements reviews

Updated plans, products, activities

People assigned responsibility and trained

Requirements metrics

$\square$ Evidence of adequate resources and tools

$\square$ Requirements management plan 
Q2.14

Requirements

Development।

Probing Questions

\section{CMMI Practices}

Additional Topics
How does your program produce and analyze customer, product, and product component requirements?

- How does your program collect and translate stakeholder needs, expectations, constraints, and interfaces into customer requirements?

- How does your program refine and elaborate customer requirements to develop product requirements for the product life cycle?

- How does your program ensure that the requirements are analyzed and validated and that the required functionality is developed?

- How does your program ensure that requirements development is institutionalized as a defined process?

- How was this process defined and where is it documented?

Does the program perform any of the following practices? Does the program perform any particularly well? Are their some the program needs or wants to improve?

- Elicit Needs

- Transform Stakeholder Needs, Expectations, Constraints, and Interfaces into Customer Requirements

- Establish Product and Product Component Requirements

- Allocate Product Component Requirements

- Identify Interface Requirements

- Establish Operational Concepts and Scenarios

- Establish a Definition of Required Functionality

- Analyze Requirements

- Evaluate Product Cost, Schedule and Risk

- Validate Requirements with Comprehensive Methods

Potential sources of exemplary practices, difficulties, or lacks

Functional architecture

Organizational process

口 Technical Solutions Plan

Requirements for verification process

Needs and/or technical performance requirements

$\square$ New/derived and/or product requirements

Evidence of adequate resources and tools

$\square$ Customer requirements documents and/or baseline 
Q2.15

Verification

Probing Questions

CMMI Practices

Additional Topics
How does your program assure that selected work products meet their specified requirements?

- How does your program establish and maintain strategies, requirements, plans, and environment for verification?

- How does your program perform peer reviews on key work products?

- How does your program ensure that work products are verified against their specified requirements?

- How does your program ensure that verification is institutionalized as a defined process.

- How does your program ensure that the Product Verification process is being followed, overall and on a day to day basis?

- How is corrective action taken when discrepancies are found in work products? When is re-verification performed?

- Do you conduct formal inspections on key work products? Are other peer reviews performed?

Does the program perform any of the following practices? Does the program perform any particularly well? Are their some the program needs or wants to improve?

- Establish a Verification Strategy

- Establish the Verification Environment

- Establish Detailed Verification Plans

- Prepare for Peer Reviews

- Conduct Peer Reviews

- Analyze Peer Review Data

- Perform Verification

- Analyze Verification Results and Identify Corrective Actions

- Perform Re-Verification

Potential sources of exemplary practices, difficulties, or lacks

- Project Verification Plan

Verification traceability matrix

Requirements traceability matrix

Effort expended for verification and rework

Work product inspection logs/results

Verification logs

- Organizational policy for product verification

- Performance and verification analysis reports

DR problem report trends/aging, etc. 
Q2.16

Validation

Probing Questions

CMMI Practices

Additional Topics
How does your program confirm that a product fulfills its intended use when placed in its intended environment?

- How does your program establish and maintain requirements, strategies, and preparation activities for validation?

- How does your program validate product requirements and products against their operational needs?

- How does your program ensure that validation is institutionalized as a defined process.

- What work products, end products, operational elements, and other life cycle elements does your program validate?

- How does your program ensure that the Validation process is being followed?

Does the program perform any of the following practices? Does the program perform any particularly well? Are their some the program needs or wants to improve?

- Establish a Validation Strategy

- Establish the Validation Environment (CL 2)

- Define Detailed Validation Procedures (CL 3)

- Perform Validation

- Capture and Analyze Validation Results

Potential sources of exemplary practices, difficulties, or lacks

Project Validation Plan

口 Validation strategy

$\square$ Effort expended for validation

$\square$ Validation reports

口 Detailed description of validation environment

Inspection and simulation analysis results

- Number of validation tests versus planned

- Acceptance test cases, procedures, and results 


\section{Process Institutionalization}

\section{Q2.17}

Process

Institutionalization

\section{Examine process institutionalization for each process area:}

- Establish and Maintain an Organizational Policy

- Plan the Process

- Provide Resources

- Assign Responsibility

- Train People

- Manage Configurations

- Identify and Involve Relevant Stakeholders

- Monitor and Control the Process

- Objectively Evaluate Adherence

- Review Status with Higher Level Management

- Establish a Defined Process

- Collect Improvement Information

\section{Relationships}

Q3.

Relationships
Considering the successes and issues talked about, how are overall strengths or weaknesses influenced by:

- program-to-program relationships

- program-to-developer relationships

- defined processes

- root causes that are outside the control of your program and more a result of constraints imposed on the system by such things as, for example, congressional mandates

- other (if the above categories are perceived by the interviewee as not being exhaustive) 


\section{References}

URLs are valid as of the publication date of this document.

[Bernard 04]

[Blanchette 05]

[Capell 04]

[DAU 05]

[DoD 95]

[HQDA 03]
Bernard, Tom; Gallagher, Brian; Bate, Roger; \& Wilson, Hal. CMMI Acquisition Module (CMMI-AM), Version 1.0 (CMU/SEI2004-TR-001). Pittsburgh, PA: Software Engineering Institute, Carnegie Mellon University, 2004.

http://www.sei.cmu.edu/publications/documents/04.reports /04tr001.html

Blanchette, Stephen, Jr. U. S. Army Acquisition-The Program Executive Officer Perspective (CMU/SEI-2005-SR-002). Pittsburgh, PA: Software Engineering Institute, Carnegie Mellon University, 2005. http://www.sei.cmu.edu/publications/documents/05.reports /05sr002.html

Capell, Peter. Benefits of Improvement Efforts (CMU/SEI-2004-SR010). Pittsburgh, PA. Software Engineering Institute, Carnegie Mellon University, 2004.

http://www.sei.cmu.edu/publications/documents/04.reports /04sr010.html

Defense Acquisition University. Glossary: Defense Acquisition Acronyms and Terms, Twelfth Edition. Fort Belvoir, VA: Defense Acquisition University Press, July 2005.

http://akss.dau.mil/jsp/glossary.pdf

United States Department of Defense. DoD 5000.52-M, Acquisition Career Development Program.

http://www.dtic.mil/whs/directives/corres/pdf2/p500052m.pdf (1995).

Headquarters, Department of the Army. Army Regulation 70-1:

Army Acquisition Policy.

http://www.army.mil/usapa/epubs/pdf/r70_1.pdf (2003). 
[Kasunic 04]

[PL 02]

[Wikipedia 05a]

[Wikipedia 05b]
Kasunic, Mark. Army Strategic Software Improvement Program (ASSIP) Survey of Army Acquisition Managers (CMU/SEI-2004TR-003). Pittsburgh, PA: Software Engineering Institute, Carnegie Mellon University, 2004.

http://www.sei.cmu.edu/publications/documents/04.reports /04tr003.html

U.S. Public Law 314. $107^{\text {th }}$ Congress. Bob Stump National Defense Authorization Act For Fiscal Year 2003.

http://www.defenselink.mil/dodgc/olc/docs/PL107-314.pdf (2002).

Wikipedia, The Free Encyclopedia. Description of "Delphi

method.” http://en.wikipedia.org/wiki/Delphi_method (2005).

Wikipedia, The Free Encyclopedia. Description of "Grounded theory.” http://en.wikipedia.org/wiki/Grounded_theory (2005). 


\begin{tabular}{|c|c|c|c|c|}
\hline \multicolumn{3}{|c|}{ REPORT DOCUMENTATION PAGE } & \multicolumn{2}{|c|}{$\begin{array}{l}\text { Form Approved } \\
\text { OMB No. 0704-0188 }\end{array}$} \\
\hline \multicolumn{5}{|c|}{ 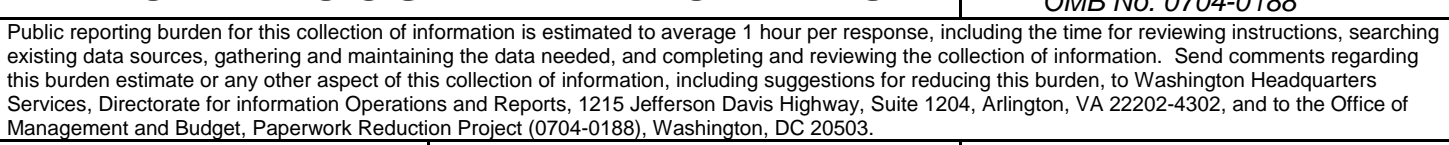 } \\
\hline (Leave Blank) & \multicolumn{2}{|l|}{$\begin{array}{ll}\text { 2. } & \text { REPORT DATE } \\
& \text { October } 2005\end{array}$} & \multicolumn{2}{|c|}{$\begin{array}{ll}3 . & \text { REPORT TYPE AND DATES COVERED } \\
& \text { Final }\end{array}$} \\
\hline \multicolumn{3}{|c|}{$\begin{array}{l}\text { TITLE AND SUBTITLE } \\
\text { U.S. Army Acquisition - The Program Office Perspective }\end{array}$} & \multicolumn{2}{|c|}{$\begin{array}{ll}\text { 5. } & \text { FUNDING NUMBERS } \\
& \text { FA8721-05-C-0003 }\end{array}$} \\
\hline \multicolumn{5}{|l|}{$\begin{array}{ll}\text { 6. } & \text { AUTHOR(s) } \\
& \text { Kristi L. K }\end{array}$} \\
\hline \multicolumn{3}{|c|}{$\begin{array}{l}\text { PERFORMING ORGANIZATION NAME(S) AND ADDRE } \\
\text { Software Engineering Institute } \\
\text { Carnegie Mellon University } \\
\text { Pittsburgh, PA } 15213\end{array}$} & \multicolumn{2}{|c|}{$\begin{array}{ll}8 . & \text { PERFORMING ORGANIZATION } \\
& \text { REPORT NUMBER }\end{array}$} \\
\hline \multicolumn{3}{|c|}{$\begin{array}{l}\text { 9. SPONSORING/MONITORING AGENCY NAME(S) AND } \\
\text { HQ ESC/XPK } \\
5 \text { Eglin Street } \\
\text { Hanscom AFB, MA 01731-2116 }\end{array}$} & \multicolumn{2}{|c|}{$\begin{array}{l}\text { 10. SPONSORING/MONITORING AGENCY } \\
\text { REPORT NUMBER } \\
\text { CMU/SEI-2005-SR-014 }\end{array}$} \\
\hline \multicolumn{5}{|l|}{ 11. SUPPLEMENTARY NOTES } \\
\hline \multicolumn{3}{|c|}{$\begin{array}{l}\text { 12A DISTRIBUTION/AVAILABILITY STATEMENT } \\
\text { Unclassified/Unlimited, DTIC, NTIS }\end{array}$} & \multicolumn{2}{|c|}{ 12B DISTRIBUTION CODE } \\
\hline \multicolumn{5}{|c|}{$\begin{array}{l}\text { The U.S. Army Strategic Software Improvement Program (ASSIP) is a multiyear effort to improve the way the } \\
\text { Army acquires software-intensive systems. As part of the ASSIP, the Carnegie Mellon Software Engineering } \\
\text { Institute (SEI) examined } 12 \text { of the Army's Acquisition Category } 1 \text { programs, using a method called Bench- } \\
\text { marking for Improvement (BFI). The purpose of conducting the BFI engagements was to define the current } \\
\text { state of the acquisition practices across the Army, to discover best practices currently in use by Army program } \\
\text { offices, and to identify the software challenges that extend across Army programs. As part of the BFI proc- } \\
\text { ess, the program management office and SEI interview teams worked together to identify Department of Army } \\
\text { best practices and shortcomings in the overall acquisition process, as well as potential solutions and recom- } \\
\text { mendations. In addition, the SEI team provided each program manager with an independent view of program- } \\
\text { level activities and made specific recommendations for improvement. A briefing provided to each program } \\
\text { manager documented these recommendations. }\end{array}$} \\
\hline \multicolumn{5}{|c|}{$\begin{array}{l}\text { This report documents the results of the interviews conducted during BFI engagements. These results are of } \\
\text { interest to Program Executive Office staffs, Program Management Office staffs, and Department of Army } \\
\text { staffs that are involved in acquisition. }\end{array}$} \\
\hline \multicolumn{3}{|c|}{$\begin{array}{l}\text { SUBJECT TERMS } \\
\text { acquisition, benchmark, COTS, integrated team, process improve- } \\
\text { ment, program management, software intensive systems, software- } \\
\text { intensive systems, interoperability, metric }\end{array}$} & \multicolumn{2}{|c|}{$\begin{array}{l}\text { 15. NUMBER OF PAGES } \\
68\end{array}$} \\
\hline \multicolumn{5}{|l|}{ 16. PRICE CODE } \\
\hline $\begin{array}{l}\text { 17. SECURITY CLASSIFICATION } \\
\text { OF REPORT } \\
\text { Unclassified }\end{array}$ & $\begin{array}{l}\text { 18. SECURITY CLASSIFICATION OF } \\
\text { THIS PAGE } \\
\text { Unclassified }\end{array}$ & $\begin{array}{l}\text { 19. SECURTYY CLAS } \\
\text { ABSTRACT } \\
\text { Unclassifie }\end{array}$ & SIFICATION OF & $\begin{array}{l}\text { 20. LIMITATION OF ABSTRACT } \\
\text { UL }\end{array}$ \\
\hline
\end{tabular}

